\title{
The Analysis on the Costs of Supervision of Insurance Solvency
}

\author{
Xiaoyu Zhang \\ Jianghan University, Wuhan, 430000 China. \\ 1299378304@qq.com
}

\begin{abstract}
The economic system of insurance plays a very important role in social stability and economic development. Because of its particularity, the insurer does not need to perform the obligations stipulated in the insurance contract at a time when the insurance contract is signed, which makes the rights of the insured and the insured in a special state. If the insurer's solvency cannot be guaranteed, the rights and interests of the insured and the insured cannot be guaranteed. Certificate. Therefore, strengthening the supervision of insurers' solvency and taking it as the focus of supervision are the key tasks of insurance supervision. The purpose of this paper is to analyze the cost of solvency supervision by paying the corresponding cost of insurance solvency supervision. The cost of insurance solvency regulation includes direct cost and opportunity cost. In this paper, the author makes an analysis of the two costs, and points out the possible errors of regulatory policy.
\end{abstract}

Keywords: Insurance Solvency, Opportunity Cost, Direct Cost.

\section{Introduction}

One of the characteristics of the insurance company is that the two sides of the insurance contract have the time asymmetry in the fulfillment of their obligations and the realization of their rights, as an enterprise that takes the risk as a business object. When the insurer comes into force, the insurer will collect the insurance fee and realize its own rights. However, the performance of the insurer should wait until a certain time, when the agreed risk accident occurs and causes the loss to bear the compensation and payment responsibility. If the insolvency of the insurance company is not enough to cause bankruptcy, the insured and the insured cannot enjoy the insurance guarantee at the time of the accident, and then affect the normal operation of the social economy. Therefore, insufficient solvency directly damages the interests of the insured and the insured.

Solvency reflects the financial safety of an insurance company and whether it can fulfill the policy obligations. The supervision of solvency is to monitor the solvency of insurance companies by means of evaluation, monitoring and inspection. If there is a special case of insufficient solvency, the regulatory authorities will take measures to make the financial situation of the insurance company tend to develop well and restore the solvency to normal. Therefore, to protect the interests of the insured, we must supervise the solvency of the insurance company, and take it as the core of supervision.

Staking and Babble (1995) research that insurance companies that are poor in solvency, unable to pay due compensation and payment obligations from the perspective of the entire insurance industry, actually undermine the image of the public in the whole industry, and have formed a negative impact on companies with good financial conditions and sufficient solvency. The influence of externality. For regulators, it is very important to monitor the solvency of insurance companies and rectified the companies with insufficient solvency. The study of Mayer's and Smith (1987) shows that the key to avoiding the insolvency of insurance companies is to have a full understanding of the financial situation, which can help the managers of insurance companies to minimize personal losses. Once the insurers are insolvable and even bankrupt, the reputation of the insurance company managers will be damaged, thereby affecting their future career. Therefore, from the personal point of view, the management of insurance companies has the power to ensure the company's sound operation by means of various means. In all aspects of insurance management, the risks are objective, and these risks are ultimately borne by the insurance companies. These risks are distributed in all aspects of the insurance operation. 
It is one of the primary tasks of insurance regulatory agencies to avoid loss of solvency to the insured and the insured. Therefore, insurance regulators in most countries invariably take solvency regulation as the focus of the insurance regulatory system in the country.

\section{The Analysis of Direct Cost}

\subsection{On-Site Inspection}

The main objective of the on-site inspection is to supervise the operation of the insurance company, the financial information and the legality of the operating activities reflected, and to evaluate the efficiency of the insurance company. Before implementing on-site inspection, detailed plans and strict implementation procedures should be formulated around the inspection targets. The main contents of site inspection include capital adequacy, reserve requirements, asset quality, profitability and solvency. The inspectors can be either the insurance supervision department or the other personnel employed by the insurance regulatory department, such as independent auditors.

\subsection{Off-Site Inspection}

The off-site inspection system refers to the establishment of the supervisory information system by the insurance supervision department. The insurance regulators collect, collate and analyze the daily supervision reports and other related materials, compare the indicators of the monitoring and the requirements of the steady management, analyze the operating conditions of the insurance companies and grasp the insurance company's compensation in time. The change in the ability to pay. The reports of insurance companies required by the insurance company regularly include the following categories: one is the reflection of business operation status, such as business statistics, sub insurance statistics, agency statistics, intermediary business statistics, etc.; two is the financial situation, such as balance sheet, profit statement, cash flow statement, and so on; three Reporting of solvency, such as solvency and regulatory indicators. In addition, it also includes the statement of funds utilization and the statement of non-performing assets. Through the analysis of the above information, the insurance regulators can timely grasp whether the insurance companies meet the requirements of the steady operation on various monitoring indicators and take appropriate regulatory measures.

Both off-site inspections and on-site inspections have made the insurance regulatory agencies and the regulated insurance companies pay a considerable price. The regulatory agency dispatched staff, and the supervised insurance companies also need to assign employees to complete these special tasks. These office costs and personnel costs constitute the main content of the direct cost of the insurance solvency regulation.

Direct costs are visible and easy to calculate. Besides, there are indirect costs in insurance solvency regulation. The obvious indirect cost is the unconventional measure taken by the supervisor to avoid the supervision. The existence of these measures increases the unnecessary cost for the insurer's operation and may even pay the illegal cost.

\section{The Opportunity Cost of Supervision of Insurance Solvency}

\subsection{The Amount of Solvency May Be Too High}

In addition to on-site inspection and non-on-site inspection, the insurance company's solvency regulation requires insurance companies to follow the provisions of the solvency quota and keep the minimum solvency quota required by the regulatory authorities, which is an important content of the insurer's sufficiency of solvency. The purpose of the concept of solvency is to measure the ability of the insurance company to repay the debt beyond the insurance liability reserve under a large area of claim that is less likely. The standard of the unified solvency is naturally the responsibility of the regulatory agency, and the concept of the solvency limit is designed. To achieve the purpose of quantifying the insurer's solvency. The concept of solvency is included in the solvency, and solvency 
covers many aspects, including solvency, of course, solvency is an important part of a lot of solvency. The solvency margin is the result of the calculation of solvency. The solvency is the capacity between the assets and liabilities of the insurance company, and the insurance company must have a certain difference between the total assets and the total liabilities (the main part is the insurance liability reserve). Only in this way, the insurance company will be able to provide the insured and the insured in accordance with the contract when the actual claim is greater than the expected claim. The actual amount of solvency can be simply described as the actual capital of the insurer minus the actual liabilities.

From the definition of the solvency limit, if an insurance company wants to maintain a certain amount of solvency and comply with the minimum requirements of the regulatory authorities, its assets must be larger than liabilities, and this gap has to be maintained at a certain level so that it can meet the requirements of the minimum solvency. In fact, the solvency margin makes the insurance company lose a lot of investment income opportunities. In theory, as long as the assets of the insurance company are equal to liabilities, they can maintain normal operation and do not go bankrupt. But because of the probability of real insurance accidents and the deviation from the expected value, the insurance company has to retain a part of the balance on the basis of balance of assets and liabilities, once the rate of payment is high. In the case of expectation, the insurance company can cope with the problem without bankruptcy. The solvency is like a pool, keeping a certain amount that is to ensure that the water in the pool has to keep a certain height, not less than the setting of a warning line. However, as a supervisor's insurance company, their idea is that the lower the solvency is, the better, because they can fully improve the use of funds without the limit of the solvency limit; on the other hand, as a supervisor, the regulator wants the greater the solvency of the better, the more the cistern line is. The higher the better, they think that this insurance company's safe operation is more secure, as for the efficiency of capital use, regulators are not included in the scope of consideration. The obvious is that the insurance company has no right to speak at the point of paying the solvency, so we have a reason to think that the minimum solvency limit held by the insurance company may be too high.

\subsection{The Opportunity Cost of Solvency Regulation}

The solvency quota of the insurance company is not fixed but changing with the change of the company's operating conditions. In the course of the operation, the solvency quota is lower than the requirement of the legal solvency, and the insurance company only needs to adjust the solvency to the police in accordance with the specific circumstances. It's on top of the line. In the light of the definition of solvency and the definition of the solvency limit, the insurance company can only recover the amount of solvency through two ways, namely, the adjustment of assets and the adjustment of liabilities. Either way, it will pay a certain opportunity cost. In order to adjust the assets, if the insurance company wants to increase the amount of solvency by means of increasing the registered capital, then the capital that can be applied to the production and operation becomes the registered capital and cannot be used for operation. This is the opportunity cost of maintaining the solvency limit.

\section{Policy Fault Based on the Supervision Cost}

First, it is worth affirming that it is very correct to pay attention to the solvency, to keep the insurance company to maintain a certain amount of solvency, so as to avoid the insolvency of the insurance company. It is only to ensure the safety of the insurance company to further discuss how to develop. However, the following problems are also very obvious. Just as Maslow divides human needs into different levels, insurance companies also have their own multi-level needs, safe operation, and cannot be bankrupt, and can be analogous to the basic human needs of survival. After this demand is satisfied, it will naturally wish to meet higher levels of demand. The author believes that as an insurance company, its higher level of demand should be the pursuit of profit. Perhaps, after the development to a certain stage, it will pursue a sense of social mission and take on social responsibility. 
If the purpose of the insurance company is to ensure more profit on the basis of ensuring safety, should the regulatory policy of the regulatory agency be adjusted accordingly?

We first look at the solvency regulatory policy that the regulatory authorities are implementing at the present stage. In a word, we need the insurance companies to maintain adequate solvency. If the early-warning system shows that the solvency of a certain insurance company is insufficient, the company should use all kinds of hand - to - pay solvency to ensure that the company is in the first place. Set the level. At first glance, it seems that this is an efficient means. But after careful consideration, the purpose of this regulatory policy is actually only one, so that insurance companies will not go bankrupt.

There is another reason why the current solvency regulation policy is a low level regulation. It is not appropriate to seize the solvency quota and pay the solvency as the focus, but only to see the image of the problem. When the regulators found that the solvency of the insurance company was insufficient, the insurance company was required to rectify and rectify the insurance company. As for the reasons for the lack of solvency, it was not included in the monitor's vision. The previous metaphor looks at the solvency as a pool, and the regulator has always stared at the water level in the pool. If the height of the water is lower and below the guard line, the insurance company is required to pour water into the pool, but if the pool itself has a loophole, the amount of water is not good, and the pool will eventually become bottomless. The hole. The supervision of the solvency is similar, and the regulatory authorities only pay attention to the insolvency of the insurance companies, but they are not actively looking for the cause of insufficient solvency. As long as this reason persists, the insolvency of the insurance companies will occur repeatedly, for regulators, insurance companies, and investment. The insurer is not a good thing. Not to solve the deep reasons, but to maintain the solvency of the insurance company, such an insurance company is a disease management, it seems that the solvency is up to the standard, the company is safe and will not be bankrupt for the time being, but in the long run, it has deepened the risk of bankruptcy. Inclusion

\section{Conclusion}

The insurance solvency supervision policy has opportunity cost and direct cost, and the direct cost is easy to observe and easy to measure. However, when it comes to the opportunity cost problem, whether it is the supervisor or the supervisor, it always faces the opportunity cost when implementing the solvency regulation policy. At present, there are problems in our country's supervision policy focusing on solvency. These problems are misled by the policy and can be said to be the solvency regulation. The opportunity cost of policy.

\section{References}

[1]. KB Staking, DF Babble, The relation between capital structure, interest rate sensitivity, and market value in the property-liability insurance industry, Journal of Risk \& Insurance , 1995, 62 (4) :690-718.

[2]. D Mayer's, CW Smith, Corporate insurance and the underinvestment problem, Journal of Risk \& Insurance, 1987,54 (1) :45-54. 